\title{
Evolution of the Instructional Design in a Series of Online Workshops \\ L’évolution d'un design pédagogique dans le développement d'ateliers en ligne
}

Anne Patry, Elizabeth Campbell Brown, Rémi Rousseau, Jeanette Caron ${ }^{1}$

\begin{abstract}
This case recounts the story of the design and production of a series of online workshops for French-speaking healthcare professionals in Canada. The project spans a couple of years and, despite encountering some challenges, succeeds in large part because of its strong foundation: the instructional design. This case study features an instructional designer from a central Canadian university and three SMEs. The main design issues highlighted are the target population's limited availability for continuing education, the SME's lack of knowledge of the instructional design process, the magnitude of this project with its national scope but limited timeframe and human resources, as well as personnel changes among the SMEs and the instructional design team. This case outlines how the project team deals with these challenges to produce a series of online workshops that provide high quality training in French to healthcare professionals across Canada.
\end{abstract}

Keywords: instructional design, educational design, e-training, online training, professionals, health, French, instructional design model, process, e-learning, online learning, workshops, continuing education

\footnotetext{
${ }^{1}$ Translated into English by Michèle Clermont.

The authors would like to thank Dr. Breanne Oryschak for her editing contributions.
} 


\section{Institutional Context}

Murroll University has a history of more than three decades in distance education. In fact, its distance education team is among the most experienced in Canada. However, few courses are offered fully online at the university. Even though many faculty have a website on the University's learning management system, most of their websites are used to supplement their face-to-face courses.

The University is considered to be a large institution with approximately 40,000 students. Its numerous support services, including the one where Arianne works, make it possible to deliver courses entirely online, in a blended format, or to broadcast via audio and video conferencing accompanied by a web component.

Thanks to its team of professionals, the Centre for e-Learning is able to support the University's faculty and services. During a meeting with the team of SMEs for this particular project, George tells them about the Centre's purpose and short history: "Our Centre was created because the University believes it is important to invest in the support of faculty who want to effectively integrate technology into teaching and learning. So when faculty want to put their courses or part of their courses online, they call us. We have one of the largest e-learning teams in Canada. Since this project is rather complex, we'll see which of our multimedia production specialists will be able to help you design these workshops, produce them, and put them online!" 


\section{The Characters}

Note: All collaborators work at Murroll University

Arianne is an instructional designer at the Centre for e-Learning at Murroll University. The goal of the centre is to support the university's professors and staff from faculties and services across campus in the design and implementation of blended or fully online courses or educational resources. Arianne has been working at this centre for several years. Prior to this, she taught at the college level for many years and gained instructional design experience in the private sector. She holds a Master's degree in Educational Technology and has designed and managed many large-scale online projects. Arianne works closely with the Centre's production team. The Director assigns her a major project...

George is the director of the Centre for e-Learning. He has run similar centres in his province and has taught at several Canadian universities.

Robert is another instructional designer at the Centre and a colleague of Arianne's. He also holds a Master's degree in Educational Technology and has taught at both the college and university levels. He eventually takes over this project from Arianne when she moves on to oversee the design and production of other projects.

The client team comprises Catherine, Brigitte and Louise. All three are subject-matter experts (SMEs) and faculty. They all have experience working in the healthcare field. Catherine is a trained physiotherapist while Brigitte is an occupational therapist who, like Catherine, is planning on pursuing a Ph.D. in Education. Louise is a trained speech therapist. She is the former 
director of her department and, along with the others, a contributor to the workshop content. All three were hired by the organization funding this project, which consists of designing and launching a series of online workshops for French-speaking healthcare professionals in Canada. The client team is particularly interested in this project because they know that there is a need for French-speaking professionals working in the healthcare field to have access to training in French while they continue to work. Currently, these professionals have limited to no access to training in French.

\section{Background}

Let's go back a few years... George, the director of the Centre for e-Learning, meets with Arianne, the Centre's senior instructional designer. He explains that this is an important project that must be put online. "A client of ours needs our help. They would like us to design five workshops on student-intern supervision and deliver them online. I know you are very busy, but could you meet with the client team to find out more about this project?" he asks her. "All I know about the project is that these five workshops need to be developed in a fairly short timeframe. We only have one year, maybe a bit longer; the good news is that we do have a substantial budget. The learners are spread out across Canada. If I understand correctly, there are many stakeholders in this project, including several SMEs." Arianne thinks about all the other projects she has to manage and deliver online that year. Seeming to read her mind, George says: "Given the dire need for training among French-language healthcare professionals and the long-standing relationship between Murroll University and the United Healthcare Practitioners Association (a fictitious name), I've decided that we must include these workshops in the 
Centre's workload. So we must meet with the client team as soon as possible to find out the scope of the project. Arianne, I want you to know that you will have my full support in managing your other commitments".

\section{Specifics of the Case}

Arianne has worked on many online projects before. What is different about this one is that she must work on five different multimedia-intensive online workshops! She foresees many challenges ahead including:

- The content varies from one workshop to the next and is written by different SMEs.

- She will be responsible for the instructional design as well as the project plan, cost estimate and schedule for each workshop.

- A variety of multimedia must be integrated into the workshops to suit the target population's characteristics.

- One of the SMEs is planning to leave part way through the project.

- Learners are spread out across urban and rural settings and, as a result, don't all have high-speed Internet connections or access to the same technology.

In addition, deadlines are tight and extending the deadlines is not an option. Given the short timeframe, hiring more staff is also not feasible. Arianne says to herself: "This really is a huge project! And I don't even know all the players yet or all the different aspects of the project..." What is more, she learns that this project must be successful because it will be made available to all healthcare professionals in Canada and the training will be recognized by several professional bodies. In the days that follow, Arianne attends meetings where she finds out a bit more about the project. 
$\mathbf{1}^{\text {st }}$ Meeting: Arianne meets Catherine, one of the SMEs. For now, Catherine seems to be her team's spokesperson. She is a trained physiotherapist and teaches at the University. She is scheduled to teach the first workshop online so she is the first to work with Arianne on the project.

Arianne is curious to find out more about the actual or current conditions (Rossett, 1987) that led to the request for the design and development of this online training for healthcare professionals. At this meeting, Catherine explains the purpose of the project and the mission of the organization that initiated it. According to the needs analysis they did, offering online training in French would meet the learning needs of these professionals who require training in student-intern supervision. Providing access to professional development activities in French, at a time when their schedule permits and without having to travel, would be ideal.

Catherine goes into a little more detail about some of the issues facing these learners:

"French-speaking healthcare professionals working in English-speaking Canada don't always feel comfortable supervising student interns and, in many cases, actually lack the necessary skills. In Canada, there are healthcare courses in English but very few in French. In certain regions, there are no courses offered in French at all. The need is clear: we must provide healthcare professionals with the opportunity to learn these supervisory skills in French. They all have access to computers but they don't necessarily have access to high-speed Internet connections. Some professionals work in very remote areas, like the North."

Arianne smiles. She understands, as she has travelled extensively in Canada and knows full well that some people live in very remote areas, far away from certain amenities. 
Over the course of her meeting with Catherine, Arianne obtains a copy of the needs analysis performed by the organization that is funding the project. She makes notes so she can share them later with her team.

\section{Learner Characteristics}

There are several issues we need to take into consideration about the learners for this project:

- When they're at work, they're busy

- Many of the learners work in rural or remote areas

- Work schedules vary

- They don't always have access to training in French in their community

- They must master basic knowledge and skills quickly and be able to transfer them into practice

- They like content that is structured, short, and straight-to-the-point

- They appreciate receiving up-to-date content that addresses current realities

Before the meeting adjourns, Arianne quickly outlines the instructional design model that her team uses: "Since there is always a lot to be done and people are called upon at different times during the design and production of the workshops, we need to agree on the process we're going to follow to get the work done." She knows she will need to present this process again later to the other SMEs, but for now, she explains it briefly to Catherine.

$2^{\text {nd }}$ Meeting: Arianne and George meet the SMEs. Everyone is introduced, including Arianne and George from the Centre, and the three SMEs: Catherine, Brigitte and Louise. As mentioned 
earlier, the three SMEs also serve as adjunct faculty at the University. They are experienced professionals and have supervised student interns for years. The organization funding the project hired them specifically to write the content and to teach or facilitate the online workshops. There is excitement in the air. They are all... how should we put it... bursting with energy! For Arianne, the key is to make the most of this enthusiasm and to channel that energy towards the work that needs to be done. Arianne is also excited about the project, because it seems that nothing can hold back the creative process.

None of the SMEs have any experience in distance education or teaching online. "It doesn't matter!" Arianne thinks to herself. "This is truly a dream team. They are open to creativity and are highly motivated." What's more, the SMEs have a lot in common: they all have teaching experience; they know the content well and they are committed to revising it; they are very concerned about quality; they are very open to the idea of teamwork; they want to learn more about education in general; and they are all available for regular meetings and phone calls.

\section{The Process and the Instructional Design Model}

During the second meeting, Arianne walks the SMEs through the design process.

"One model that works very well is the systematic approach described by Brien (1997) [Figure 1] based on Gagné and Briggs model. It all starts with the needs analysis. Since you have already clearly defined those needs, we can start formulating the learning objectives right away. Once we identify the objectives, we can structure the content to ensure that it aligns with the objectives and how the learners will be assessed. After that, we need to make choices about teaching methods, learning activities and multimedia. Then we can produce an initial prototype and pilot test it to see if the choices we made work well. It may require some revisions before we can continue with the development. More pilot testing and revisions will follow and then we can deliver the workshops!" 


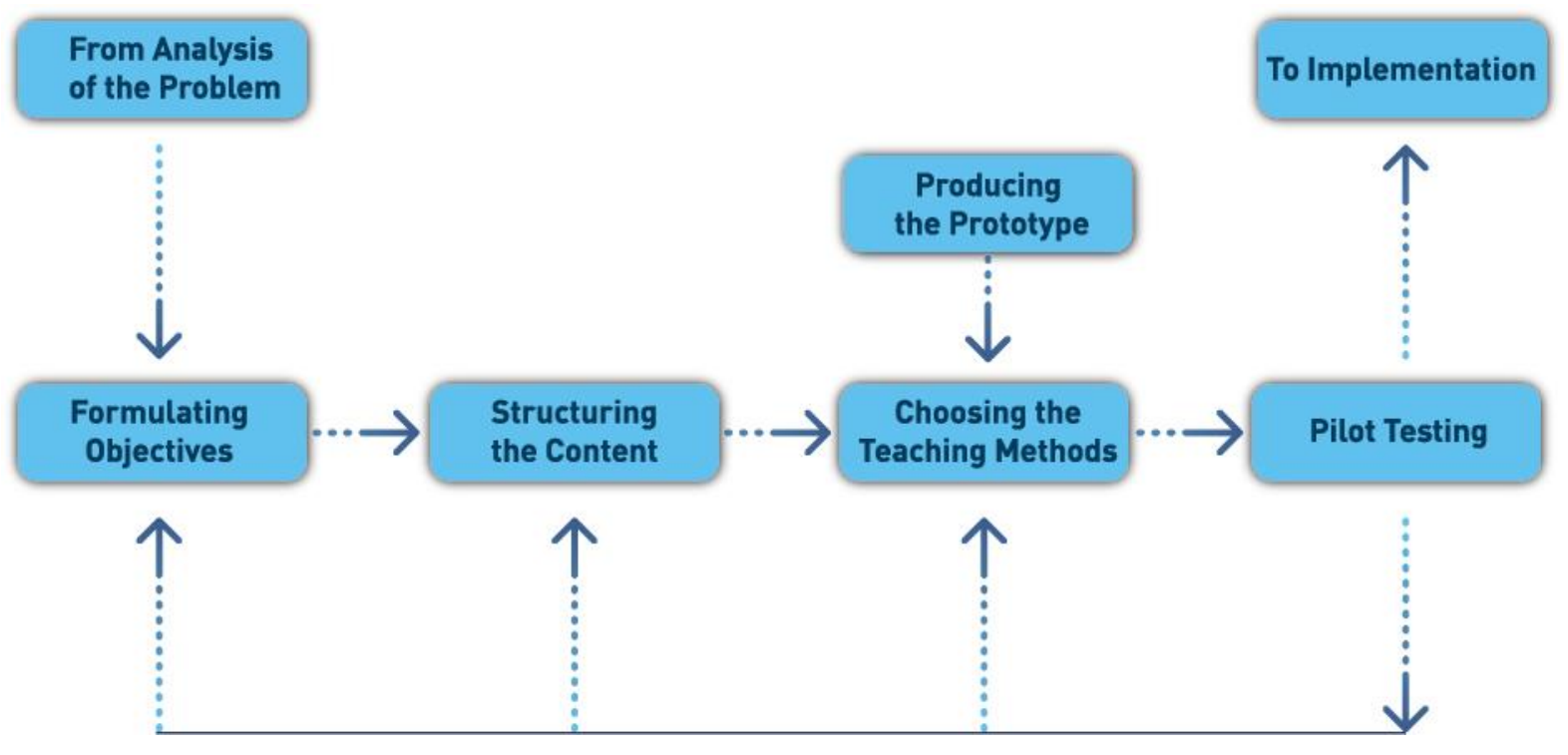

Figure 1: Systematic design of instruction model according to Brien (1997) [translated by the authors]

Louise thinks this model will help them navigate their way through this new challenge. "It seems perfectly logical to me! I like to be organized and this model will help because we have never done anything like this before. When do we start?!"

Arianne explains that formulating the learning objectives can take some time: "I suggest we start by setting aside several half days to work on this. It's best to get a head start on the objectives so that we don't forget any of our ideas or lose our momentum!" Everyone agrees. They come up with a schedule that suits everyone. Ariane adds:

"You know, this systematic approach serves as a guide. I am inspired by this model because, in my opinion, it works really well. The important thing is that the learning objectives are aligned with the learning activities and the assessment measures. This is an iterative process, which may require us to go back over previous steps as well as look ahead to the steps still to come. You should know that the objectives can also be revised later in the process because sometimes this step is misunderstood and can be tricky to work through initially. SMEs often 
focus too much on the content. But don't worry, we'll get there! Look, I even have a list of action verbs that can help us!"

George suggests that once the objectives are formulated and the content written, they should meet with the production team. Arianne adds: "Our team of production experts likes to take part in the discussions right from the start. They often leave those meetings with some initial ideas and can then begin their research."

After working for several weeks on it, the SMEs have clearly identified, revised, and validated the learning objectives. They want to follow the suggested instructional design process, but they decide to tackle one workshop at a time. Arianne informs her director. "George, after discussing it with the production team, we agreed that the first workshop will be designed and developed, at least in part, before we start working on the others." "I have complete confidence in you!" George replies.

For Arianne, the needs analysis has become a crucial part of the process. In an e-mail, she writes: "In the past, I have seen projects that follow a systematic approach and are produced on time and budget without necessarily meeting the learners' needs, realities or general learner characteristics. It's such a waste of time and resources, don't you think?" In other projects where Arianne has observed this shortcoming, it clearly comes out in the evaluation of the online projects. She recommends: “Let's be careful with our online workshops! Let's make sure we take the learner characteristics into consideration and align their training needs and realities with the choices we make." 
Arianne and the SMEs meet again several times to continue structuring the content, choosing the learning activities and developing the assessments.

With the first workshop, Arianne begins drafting a comprehensive, detailed design document. She thinks she is doing the right thing by fully describing and justifying the team's pedagogical, technological and logistical choices. But now she realizes that nobody actually reads these detailed design documents. They take up an awful lot of time and, even though the resulting documents are well written, very descriptive and reflect the teams' decisions, they prove to be an arduous task that sometimes slows down the production process. Arianne seriously considers abridging the documents, simplifying the format, and sticking to what is absolutely essential.

The result is convincing: her new design documents are just as informative, only shorter. They deal strictly with the elements pertaining to the workshop and that have a direct impact on the SMEs' work, namely: the learning objectives, structure, choice of activities and multimedia, and the assessment strategies.

Arianne schedules a meeting with the web production team to discuss the tasks related to the development of the online workshops. While working with the SMEs, Arianne reminds them:

"Even if the first workshop is not completely finished, the graphic designer and web programmer can produce a prototype and put it online. Then you can see what it looks like when we align the objectives, the content, the learning activities and assessments. We'll be able to pilot test this prototype with a couple of learners before continuing our work on the first workshop. This will also help us plan the other online workshops." 
Catherine likes what she hears. She concludes: "I'm very visual, so for me, that would be very useful. Right now we're hard at work writing down our ideas, coming up with activities together but, because we've never done this before, it's hard for us to 'see' the final product." Louise and Brigitte agree.

Gradually, the selected activities, multimedia and assessments become clearer. For the instructional design and web production team, it also becomes clear that this project is a major undertaking. The interactive activities and the multimedia being integrated into these online workshops are quite innovative for their time. For example, integrating case studies with animation or video, making use of automated feedback, and including scenarios that are interactive or narrated and illustrated by a cartoonist have rarely been done online at this university. However, Arianne's team, which includes a project coordinator, a programmer, a graphic designer, a videographer, a photographer and an audio and video production technician, is up to the task.

The work progresses over the next few months and the workshops begin to take shape. "The great thing about it," observes Catherine, who is very satisfied with Arianne's work, "is that the structure is consistent from one workshop to the next. Our health professionals will appreciate that because it will make it a lot easier for them. They will know what to expect from one workshop to the next."

In general, the workshops follow a structure similar to this: 
Table 1 - Structure of a Sample Workshop

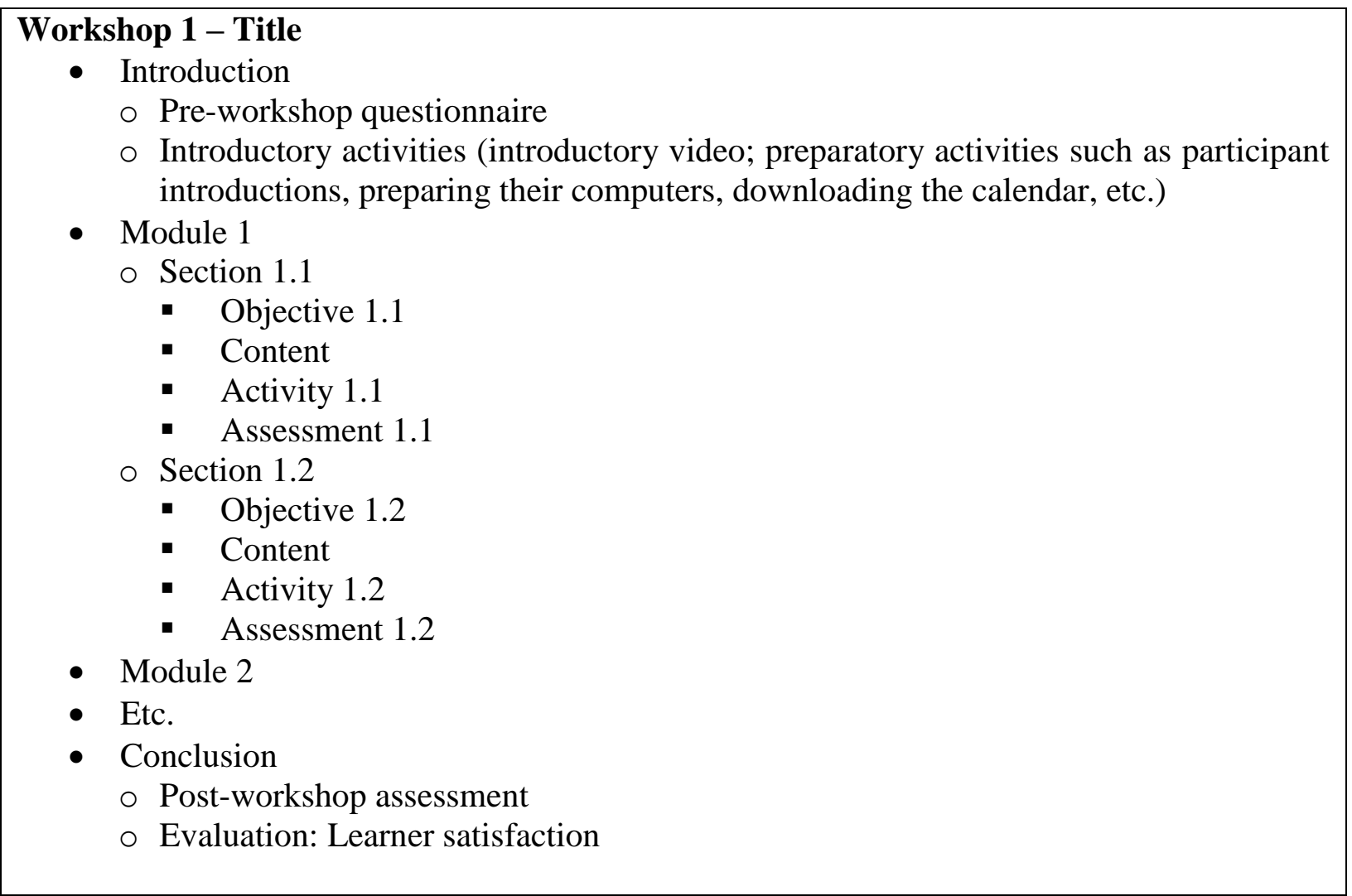

While pilot testing the first workshop, the team of SMEs notice that while some of the activities align with the learning objectives and learner needs, not all are well suited to an important learner characteristic: differing work schedules. For example, one of the activities invites learners to discuss student intern attitudes and behaviours in real time via an online chat. Although the learners say they like this type of exchange with other healthcare professionals, few of them actually show up in the chat room at the designated time. A change is in order and the SMEs suggest changing the design of this type of activity. Arianne recalls something Brigitte said in a previous meeting:

"The participants really enjoy meeting in real time, but some of them have a schedule that simply doesn't allow for it. Others have had problems getting connected." 
Arianne agrees. The real-time discussion activity is transformed into a series of asynchronous discussions in an online forum. Little by little, Arianne and the SMEs upload case studies describing real-life situations that address student intern attitudes. The team later learns that this solution was one of the things the healthcare professionals appreciated the most about the training they received.

\section{Some Challenges and Solutions}

Workshop design, production, and online delivery continue over the next couple of months. Arianne is called upon to perform other tasks so she has to pass this project on to Robert, who is also an instructional designer but has not been very involved in the project up until now. At this stage in the project, Arianne and George feel the need to review, for Robert's benefit, three main challenges encountered by the team thus far:

Challenge 1: Lack of Knowledge of the Instructional Design Process and the Instructional Designer's Role

Challenge 2: Project Scope and Deadlines

Challenge 3: Changing Personnel 


\section{Challenge 1: Lack of Knowledge of the Instructional Design Process and the Instructional Designer's Role}

The instructional designer's profession is misunderstood at the University. Arianne and her colleagues find that faculty at their university tend to fit the following profile: they are accustomed to working on their own, both in their research and in their teaching. Faculty do not grasp the importance of the input an instructional designer and a production team can provide until they have gone through the process themselves and produced one of their own courses. In fact, Arianne and the Centre's other instructional designers report that they often hear faculty asking: "What is it that you do exactly?" Many ask, skeptically, "You can help me? Really?" While others state: "What? Follow a systematic process? Maybe when I have the time...!"

Arianne and Robert agree that some faculty do not understand the instructional design process well if they have not experienced it. "Not only do they not understand it, but they don't quite grasp what it is that we do!" says Arianne. Fortunately, in the case of the current workshops, the SMEs are all willing to learn. Robert adds: "It's only after going through some of the steps of the course design process with an instructional designer that they realize what our role in the process is. It's a real discovery for them. It's only after the fact that they realize how important it is to write measurable learning objectives and that, in the end, everything must be aligned with those objectives: the content, activities and assessments." Arianne and Robert have heard many faculty say they would like to apply instructional design to their other courses and to experiment with active learning. Adrianne adds, "You'll see: the SMEs for these workshops are champions of instructional design now! They are very well organized and they follow the process meticulously!" 


\section{Solution: Pairing Up Faculty}

Arianne:

"You know, Robert, I've been thinking. Why not invite faculty who are just getting started on writing the content for a workshop to work with a professor who has already done it? It's normal for them not to understand the process because it's brand new to them. I think it would be interesting to pair up two SMEs, one who has experience with the process and one who doesn't. That way, the one who hasn't been through the process could benefit greatly from the other's experience and see how it applies to an actual course. They could discuss the role of an instructional designer and talk about how valuable his or her expertise can be for faculty launching their first online project."

Robert admits that the idea is interesting and plans to explore it further.

\section{Challenge 2: Project Scope and Deadlines}

Arianne reminds her colleague that for the next phase of the project, there is a whole series of steps to be taken and tasks to be completed.

"This project encompasses five workshops that need to be designed, created and put online, each with its own delivery date that we've had to respect in spite of the short timeline we've had for implementing all of the workshops. The decisions that we make on paper must be turned into a reality! This will mean a fair amount of work on your part and the team because the workshops are multimedia intensive and that, as you know, is resource intensive!"

\section{Solution: Planning}

Arianne describes how she has been planning the workshops one at a time, following the steps in the instructional design process. In the very beginning, when everything is new for everyone, it's difficult to figure out how long each task will take. As the project progresses, however, it's possible to do a more accurate estimate. So with time and experience, Arianne and her team can accurately estimate the time it will take to accomplish each task. Arianne is also writing simplified instructional design documents that get straight to the point. She simply outlines the 
structure of the content and lists the titles of the modules and sections, the learning objectives along with the chosen activities and multimedia, without explaining the relevance of the activities or justifying them. This reduces the writing time, which in turn reduces the design time. In the end, she produces a simplified instructional design document that reflects the decisions the team has made. To ensure that everyone - including herself - keeps on top of the tasks they have to do, Arianne decides to hold short meetings on a regular basis. This translates into the production team meeting for half an hour on the first day of the week and then again at the end of the week to review their respective tasks.

\section{Challenge 3: Personnel Turnover}

Arianne worked with a relatively consistent team of SMEs. However, a number of administrative changes took place within their team during the design and production process. Some of the SMEs left or were appointed to executive positions and were replaced with someone new. So on several occasions, Arianne had to deal with people who had never experienced the instructional design process but who, once again, wanted to learn quickly because they had a workshop to deliver.

"You'll see, Robert, the new SMEs are all very enthusiastic. They have a lot to learn but, believe me, they are highly motivated!" Arianne assures him.

\section{Solution: Identifying a Coordinator}

After experiencing some difficulties after the departure of one of their colleagues, the SMEs decided to choose a coordinator who would play a pivotal role in collaborating with the design and production team. After a little while, the SMEs become accustomed to the process and the steps leading up to the delivery of a workshop. From then on, they concentrate their efforts on 
writing content and designing learning activities, while the coordinator troubleshoots problems and submits their content to Arianne.

Arianne makes a suggestion to Robert: "We could do the same at our end. You can take over, but I can help whenever you need me. That way, we can work on updating the workshops without both of us attending all of the meetings. We'll save time, that's for sure!'

Robert adds that ever since the SMEs have assigned a coordinator to their team, their communications to the design and production team are more consistent. Not only that but having the same instructional designer working with them enables them to identify what works well to standardize the way they work. Robert sums it all up:

- The content is better structured than ever before because the same person is coordinating all of it.

- Now that the SMEs can focus exclusively on content, it is much richer, not to mention more up-to-date.

- Improving the way both teams work has freed up the Centre's team to focus on making the websites more visually attractive.

\section{Findings: Evaluation of the Online Workshops}

Evaluation tools (pretest, post-test, and evaluation rubric) are an integral part of the online workshops designed to gather data on learner knowledge before and after the training, the quality of the online training, as well as learner satisfaction levels. Through participant feedback, the design and production team is able to collect data regarding - among other things -_content, 
structure, clarity of learning objectives, selection of activities, and quality of discussion topics. These results enable them to make necessary adjustments.

Since Arianne is handing the project over to Robert, she wants to make sure he has all the essentials. She doesn't want to leave him on his own without sharing some of her experiences. To ensure that no important or useful information falls through the cracks, she meets with Robert to tell him about the project close-out document (A Guide to the Project Management Body of Knowledge, 2013) she is preparing. Arianne explains that in general, workshop participants are satisfied. She passes on some recent evaluation data from workshop participants, which reveals that:

- The objectives were clearly defined.

- The workshops were practical and useful.

- The online exchanges received mixed reviews with respect to learning benefits and advantages.

- The downloadable documents were useful.

- The learning activities provided some variety, were interesting and a useful way to learn. They helped learners achieve the learning objectives. Favourites included the videos, scenario-based simulations, matching exercises, feedback on activities and guided reflection questions.

- Some participants appreciated the animations with audio. 
- The system does not track participants who complete the module or activity. If a participant leaves in the middle of a module and returns a few days later, there are no bookmarks indicating where s/he left off.

- There were a few problems technical in nature.

- Overall, participants were highly satisfied with the training received, with all but one participant "strongly agreeing" with its effectiveness.

\section{A SME's View on the Instructional Designer's Role}

As one of the SMEs co-writing content for several of the workshops, Louise wanted to give us her feedback on the role of the instructional designer. "Here is what she wrote in an e-mail she sent me," Arianne tells Robert.

"We appreciate it when you give us new ideas for instructional activities. For example, in one of the workshops, I wanted to do something different but I couldn't come up with anything. I decided to call you, Arianne, do you remember? You suggested I try a crossword puzzle. Of course, it was perfectly suited to the learning objective!" And she added: "We find it really helpful when you read the content and suggest different ways of organizing it! And it's great that you put the content online one section at a time so that we can see how it looks on the Web. Even if it is not completely developed, we can provide you with meaningful feedback because we can actually see what the final product will look like!"

\section{Project Closure}

After meeting with Robert, Arianne starts writing her project close-out report: 
"The workshops have been reviewed and revised on an ongoing basis. The instructional design remains consistent but the learning activities and multimedia have changed. This is by design. The team have made pedagogical and technological choices based on learner realities and characteristics as well as on new technological developments. Here are a few examples of aspects that were changed in response to SME and learner suggestions:

- A more user-friendly interface

- A new way of embedding videos and multimedia for easier viewing

- Case studies presented either as videos or comic strips to make them more fun, entertaining, and interactive

- More accessible programming for interactive activities (replacing games programmed in Flash by jQuery, for example)

The online workshops are redesigned to keep up with advances in technology. The choice in technology must be reviewed and changes made according to the realities of learners in the field. All choices relating to the activities and multimedia must take into account accessibility, current realities facing the participants, and technological constraints. This is one of the reasons for the online workshops' success. These workshops address the real educational needs of very busy professionals who are required to complete training on an ongoing basis."

Postscript - The five basic training workshops remain in place and are gaining in popularity. In fact, they have stood the test of time despite changes to the team, content and technology! The first workshops designed and developed years ago are still offered today, but the content and activities have evolved over the years. Other workshops have been added and developed over 
time, including one on The Art of Supervising Student Interns. The online series contains five "basic training" workshops, plus five "advanced training" workshops. There is also a self-paced workshop available on CD-ROM and a corresponding online version. The technology used in the workshops and the instructional choices of a few activities are currently being updated, but the global design for each workshop has remained essentially unchanged.

\section{Conclusion}

The series of basic workshops on student-intern supervision for French-speaking healthcare professionals is a success, but it was not always a smooth ride. In retrospect, Arianne can see many lessons learned as a result of this experience. She recommends making it a top priority to take the time to do the initial planning. Due to the number of stakeholders involved, Arianne considered it important to organize the work to be done by following a systematic design model and production process and by writing short and precise design documents, which clearly communicated tasks and decisions for both teams involved. In addition, regularly-scheduled meetings ensured that the decisions made were communicated to and understood by both the Centre's team and the client's team. Identifying a coordinator from each team helped streamline the process and ultimately enabled the workshops to be delivered within the allotted timeframe. Finally, deciding to pair up SMEs brought consistency to content development and even made the job easier for those newly hired. Today, the workshops are still online and are increasing in popularity. They are evolving as the technology changes, but of course, these updates come with a price tag. Updating the workshops is always dependent on funding. 
On a separate note, the University has just introduced an initiative to support the design and development of a new wave of both blended and fully online courses. This new initiative targets courses from all disciplines at all levels and will be launched over the coming years.

It is because of initiatives like these that faculty are being introduced to teaching online and, based on their responses, are finding it to be a positive experience. As an added bonus, they are also able to transfer what they learned to other courses they are teaching. Some of them have remarked to us: "Your service and your profession deserve to be better known. All faculty should benefit from your services to ensure better quality teaching!"

\section{References}

Brien, R. (1997). Science cognitive et formation (3 éd.). Sainte-Foy, QC: Presses de l'Université du Québec.

A Guide to the Project Management Body of Knowledge (PMBOK Guide) (5th Ed.). (2013). Newtown Square, PA: Project Management Institute.

Rossett, A. (1987). Training needs assessment. Englewood Cliffs, NJ: Educational Technology Publications. 